\title{
Mechanical Behaviors of CFRP Laminate Composites Reinforced with Aluminum Oxide Powder
}

\author{
Oh-Heon Kwon*, Yu-Seong Yun** and Yeong-Rok Ryu***
}

(Received 29 October 2014, Revised 02 December 2014, Accepted 03 December 2014)

\begin{abstract}
In this study, a laminated composite material with dispersing aluminum oxide powder between the CFRP laminate plies, and also CFRP composites without aluminium oxide powder were fabricated for Mode I experiments using the DCB specimen and a tensile test. The behavior of the crack and the change of the interfacial fracture toughness were evaluated. Also in order to evaluate the damage mechanism for the crack extension, the $\mathrm{AE}$ sensor on the surface of the DCB test specimen was attached. AE amplitude was estimated for CFRP-alumina and CFRP composite. And the fracture toughness was evaluated by the stress intensity factor and energy release rate. The results showed that an unstable crack was propagated rapidly in CFRP composite specimen along with the interface, but crack propagation in CFRP-alumina specimen was relatively stable. From results, we show that aluminium oxide powder spreaded uniformly in the interface of the CFRP laminate carried out the role for preventing the sudden crack growth.
\end{abstract}

Key Words : Carbon Fiber Reinforced Plastic, Laminates, Aluminum Oxide Powder, Fracture Toughness, Acoustic Emission

\section{Introduction}

The fiber reinforced plastic(CFRP) materials have been developed as the advanced composite materials in the several industrial fields as like mechanics, electricity, structure and others during a few decade. Especially CFRP composites have been applying to the aerospace and vehicle for the lightweight design owing to the high specific strength and modulus ${ }^{1)}$. However, CFRP composites

$* * \dagger$ Yu-Seong Yun (corresponding author) : IBS Innovation

Co. E-mail : planet70@naver.com, Tel : 051-629-6469

*Oh-Heon Kwon : Department of Safety Engineering, Pukyong National University.

***Yeong-Rok Ryu : Department of Safety Engineering, Graduate School, Pukyong National University must be fabricated by the laminating method for the useful thickness. Therefore, the delamination situation happens often in the interface of the laminated plies and it can induce ${ }^{2)}$ the sudden crack extension and fracture of the structures. Thus, the improvement of the fracture toughness of the interface between the laminate plies becomes an important key role to obtain the safety and healthy condition of the CFRP composite structures. Many researchers $^{3 \sim 5)}$ have studied by the several methods for the interlaminar fracture of the CFRP laminate composites. However until now the researches for the CFRP composite with the interlayer spreaded the reinforced powders between the laminates have not been done sufficiently. In this study, the CFRP-alumina composite spreaded with aluminum oxide powder in the interface between laminates 
was evaluated for the fracture toughness. And the evaluation for restraint properties of the crack extension under the DCB(Double cantilever bending) test ${ }^{6}$ and also $\mathrm{AE}$ characteristics experiment were implemented to estimate the crack behaviors. The experiments were performed by using the two kinds of specimens of the only CFRP prepreg laminate and CFRP laminates spreaded and reinforced by aluminum oxide powders in the interface. Also the tests were implemented with $\mathrm{AE}$ sensors under the tension loading and DCB condition for the mechanical properties and interlaminar fracture toughness evaluation.

\section{Experimental materials and method}

\subsection{Materials}

The CFRP material was a woven type carbon fiber reinforced prepreg(Hankuk Cabron Co.) and an aluminum oxide powder has particle size of $1 \mu \mathrm{m}$ (R\&B Inc.). The CFRP prepreg was cut to a size of $250 \mathrm{~mm} \times 250 \mathrm{~mm}$ square and laminated with 12 plies. One type is laminated with only CFRP prepreg and another type is laminated by CFRP prepregs with an aluminum oxide layer between sixth and seventh ply. The powder mixed in a ratio of 1:5 with an ethanol was sprayed evenly over the prepreg to make the uniform aluminum oxide layer. From now, the specimen laminated with only CFRP prepregs

Table 1 Composition of the fiber and resin in CFRP prepreg

\begin{tabular}{lc}
\hline Material(CF 3327EPC) & Value \\
\hline Fiber Wt. $\left(\mathrm{gr} / \mathrm{m}^{2}\right)$ & 205 \\
Resin Wt. $\left(\mathrm{gr} / \mathrm{m}^{2}\right)$ & 148 \\
Total Wt. $\left(\mathrm{gr} / \mathrm{m}^{2}\right)$ & 353 \\
Thickness, $\mathrm{t}(\mathrm{mm})$ & 0.27 \\
\hline
\end{tabular}

Table 2 Engineering properties of aluminum oxide powder

\begin{tabular}{ll}
\hline Material(AP-100) & Value \\
\hline Density $\left(\mathrm{g} / \mathrm{cm}^{3}\right)$ & 3.97 \\
Flexural strength $(\mathrm{MPa})$ & 379 \\
Elastic modulus $(\mathrm{GPa})$ & 373 \\
Poisson's ratio & 0.22 \\
\hline
\end{tabular}

is called as $\mathrm{C}$ type specimen and the CFRP laminate reinforced by the aluminum oxide powder is called as CA type specimen. Table 1 shows composition of the resin and carbon fiber of the CFRP prepreg and Table 2 shows the engineering properties of the aluminum oxide powder used in the experiment. The composite laminates were formed at $130^{\circ} \mathrm{C}$ temperature during 1 hour in the hot press for a hardening. The final thickness was about $3.10 \mathrm{~mm}$ for CFRP laminates and was obtained about $3.25 \mathrm{~mm}$ in CFRP laminates reinforced by aluminum oxide powder. The hardened composite laminate was machined as the tensile and DCB test specimen according to the ASTM D30397) and D5528 ${ }^{8}$, respectively.

Fig. 1 shows the figuration and dimension of the (a)tensile and (b)DCB test specimen. A thin aluminum tab is attached on the both ends of the tensile specimen by using an araldite epoxy resin with a hardner to prevent a damage and slip from the fixture of the machine. The bonding surfaces are scratched with an emery paper of $\# 100$ and cleaned by acetone solvent. And the tab has been taped with angle of $30^{\circ}$ to prevent a stress concentration. On the other hand, the square aluminum blocks were attached on the end of DCB specimen and treated in the same method as the tensile specimen. The fabricated tensile and DCB specimens with tabs or blocks were cured in the electric furnace at $100{ }^{\circ} \mathrm{C}$ during 30min. The precrack was formed by inserting a thin cooking foil on the DCB specimen and the 
final crack length of $a_{0} / L=0.3$ was formed by inserting a fatigue crack as $2 \sim 3 \mathrm{~mm}$ under a dynamic universal test machine.

Unit : $\mathrm{mm}$
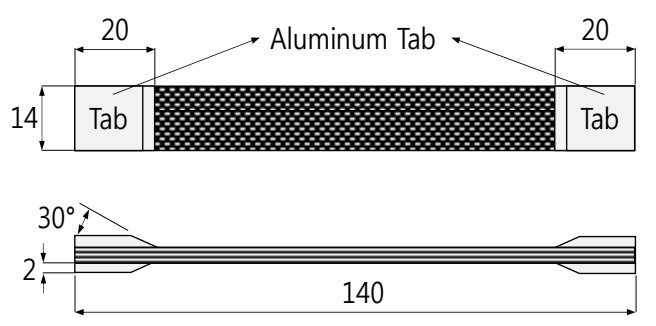

(a) Tensile test specimen

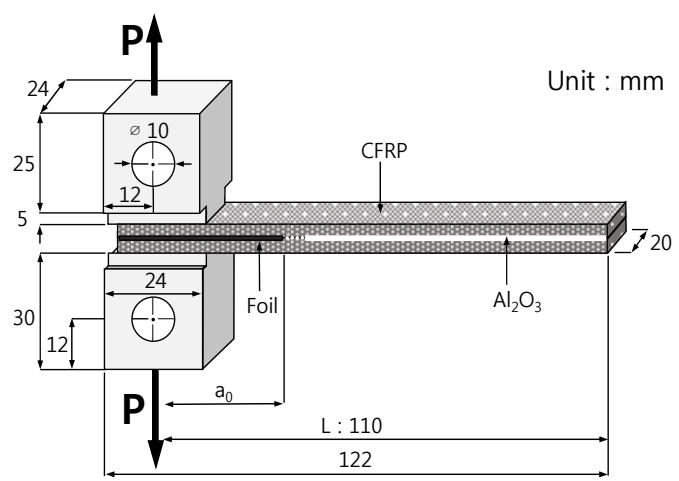

(b) DCB test specimen

Fig.1 Configuration of specimens

\subsection{Experimental methods}

A tensile test was carried out by the displacement control $(1 \mathrm{~mm} / \mathrm{min})$ by using a universal test machine $(50 \mathrm{kN})$, and the strain in the center of the specimen was obtained by attaching a strain gauge. The DCB fracture test was performed by the mini tensile tester(Tinus Olsen Inc., $5 \mathrm{kN}$ ) with $0.5 \mathrm{~mm} / \mathrm{min}$ displacement control. A crack extension length was measured by using a stereoscopicmicroscope and recorded through a digital converter. AE system with a built-AEDSP32 board was used for $\mathrm{AE}$ characteristics measurement about damage assessment under fracture tests. The AE sensor R15 of resonant frequency $150 \mathrm{kHz}$, which has a band-pass filter of from $100 \mathrm{kHz}$ to $300 \mathrm{kHz}$, was used. And a silicone as a contact medium was placed between the specimen and the sensor and the $\mathrm{AE}$ sensor was pressed by the cloth tape in order to improve the transfer efficiency of the $\mathrm{AE}$ signals.

\section{Results and discussion}

\subsection{A mechanical behavior for a tensile test}

Fig. 2 shows stress-strain relationship curves by a tensile test for two types of specimen, which one is made up with only CFRP composite(C type) and another is CFRP composite with aluminum oxide powders (CA type).

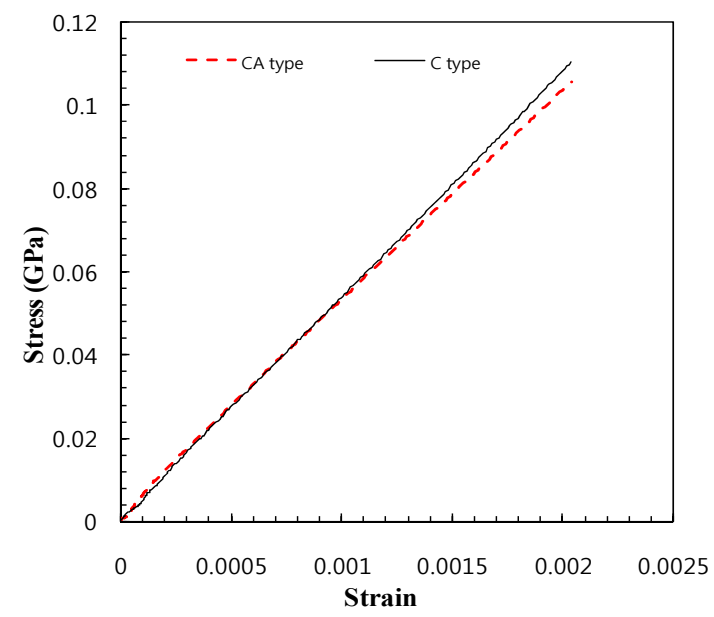

Fig. 2 Stress-strain curves for CFRP composite (C type) and CFRP-alumina composite (CA type) under tensile test

Table 3 Mechanical properties of specimens

\begin{tabular}{ccc}
\hline Specimen & $\begin{array}{c}\text { Elastic Modulus, } \\
\text { E }(\mathrm{GPa})\end{array}$ & $\begin{array}{c}\text { Poisson's ratio, } \\
v\end{array}$ \\
\hline C type & 54.12 & 0.05 \\
CA type & 53.01 & 0.07 \\
\hline
\end{tabular}


The results in two types of the specimen are almost the same. The obtained mechanical properties are shown in the Table 3 .

\subsection{Interlaminar fracture under DCB test}

Fig. 3 shows the relationships between the load and displacement and crack extension length under mode I test using DCB specimen for two kinds of specimen. The load in each type specimen was increased linearly until the maximum load point. The maximum load was about $49 \mathrm{~N}$ and $37.5 \mathrm{~N}$ for the $\mathrm{C}$ type specimen and CA type specimen, respectively, even though the pop-in was occurred in CA type specimen. The crack initiated directly after the sudden load drop as the crack length becomes $6.45 \mathrm{~mm}$ and $0.42 \mathrm{~mm}$, respectively. After first initiating, the crack extension and load drop were intermittent at both types of specimen and the last crack extension length was $42.41 \mathrm{~mm}$ and $43.23 \mathrm{~mm}$ at the same displacement of $20 \mathrm{~mm}$, respectively. The load reduction average is about $2.575 \mathrm{~N}$, which changes from $0.35 \mathrm{~N}$ to about $7.3 \mathrm{~N}$ and the change in the displacement was obtained as the average of about $0.5 \mathrm{~mm}$ to a minimum of about $0.03 \mathrm{~mm}$ up to about $2.01 \mathrm{~mm}$ in the case of CA type specimen. In

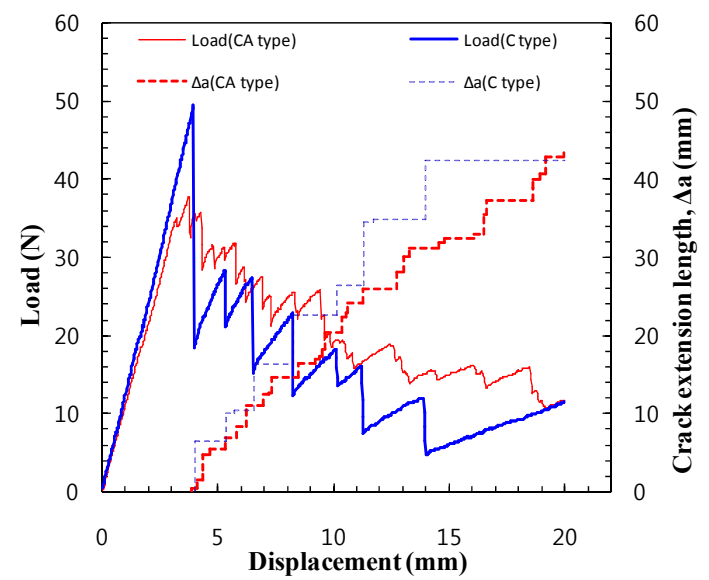

Fig. 3 Load-displacements and crack extension length variation of DCB fracture test the case of $\mathrm{C}$ type specimen, load was reduced an average of about $11.65 \mathrm{~N}$, and an average change of the displacement showed $1.77 \mathrm{~mm}$. From the results, load reduction ratio in CA type specimen which the aluminum oxide powder is spreaded was stable more $75 \%$ than that of $\mathrm{C}$ type specimen. It is expected to act as a stabilizer to inhibit a sudden crack growth by the thin aluminum oxide powder layer in the interface of CFRP laminate composite. Fig. 4 is a typical model of observing the shape of the crack growth in CA type.

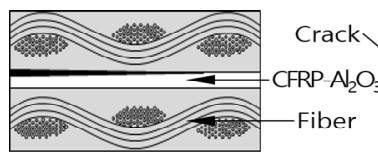

(a) Type I-1

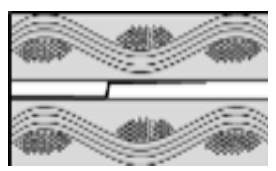

(c) Type I-3

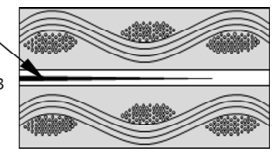

(b) Type I-2

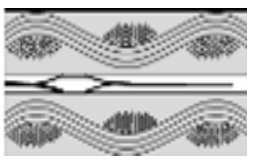

(d) Type I-4
Fig. 4 Schematic four models of crack growth acquired from a fracture test(CA type specimen)

They show that (a)Type I-1 indicates the growth of cracks along the interface between the laminated CFRP layers and aluminum oxide powder, (b)Type I-2 indicates the growth of cracks in the inner of aluminum oxide powder, (c)Type I-3 shows the growth of cracks along the other side of the interface again across the aluminum oxide powder layer while growth of cracks along the interface of CFRP laminate with aluminum oxide powder layer. (d)Type I-4 shows the form of a growing crack in both interface based on the aluminum oxide powder layer. Fig. 5 is a typical model corresponding to the progress observed crack growth shape in the $\mathrm{C}$ type specimen. Fig. 5(a) shows the growth of cracks along the carbon fiber direction of $0^{\circ}$, and (b) indicates the crack growth in accordance with the 
interface of the laminate. Fig. 5(c) shows that the crack growth along the $0^{\circ}$ weft fiber layer interface advances through the interlayer, (d) represents the crack combined with each other to grow into $0^{\circ}$ fiber orientation. The most typical crack growth model is Fig. 4(a) and (c) in the case of CA type specimen and Fig. 5(b) in the case of $\mathrm{C}$ type specimen expects the sudden load drop and crack growth.

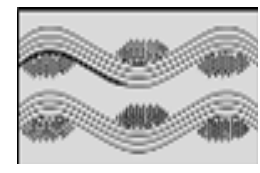

(a) Type II-1

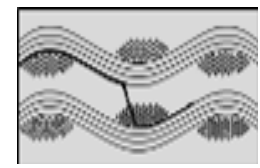

(c) Type II-3

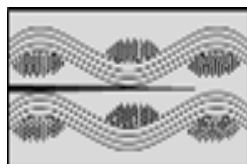

(b) Type II-2

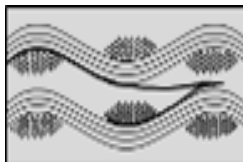

(d) Type II-4
Fig. 5 Schematic four models of crack growth acquired from a fracture test( $\mathrm{C}$ type specimen)

\subsection{Interlaminar fracture resistance evaluation under DCB test}

Fig. 6 shows the relationships between the crack extension length $(\Delta a)$ and stress intensity factor $K_{I}$. The fracture toughness for a mode I fracture test can be found by the following equation $(1)^{9)}$.

$$
K_{I}=\frac{2 \sqrt{3} P a}{W(B / 2)^{3 / 2}} \cdot\left[1+0.639\left(\frac{B / 2}{a}\right)\right]
$$

Here $\mathrm{P}, \mathrm{B}, \mathrm{W}$ and $a$ are load, thickness, width and crack length, respectively.

The mode I fracture toughness $\mathrm{K}_{\mathrm{IC}}$ was estimated as about $2.91 \mathrm{MPa} \cdot \mathrm{m}^{1 / 2}$ and $4.41 \mathrm{MPa} \cdot \mathrm{m}^{1 / 2}$ in $\mathrm{CA}$ type and $\mathrm{C}$ type specimen, respectively. While the fracture resistance of the CA type specimen tends to decrease progressively, fracture resistance in $\mathrm{C}$ type specimen tends to be lowered suddenly as a crack grows rapidly. A stress intensity factor fracture toughness $\mathrm{K}_{\mathrm{IC}}$ in the $\mathrm{C}$ type specimen is higher than $\mathrm{K}_{\mathrm{IC}}$ of $\mathrm{CA}$ type specimen. However the fracture resistance value of CA type specimen is higher than that of $\mathrm{C}$ type specimen after the crack advanced.

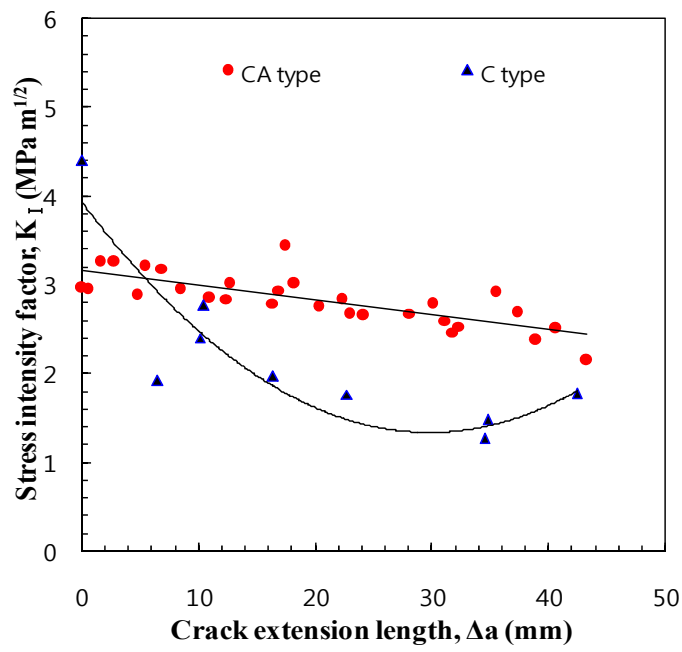

Fig. 6 The interlaminar fracture toughness resistance by the stress intensity factor $\mathrm{K}$

Furthermore mode I energy release rate $G$ under DCB test was obtained by using MBT (Modified Beam Theory) formula (2) on the basis of the ASTM D 5528-018).

$$
G_{I}=\frac{3 P \delta}{2 B(a+|\Delta|)}
$$

Here, $\mathrm{P}, \delta, \mathrm{B}, a$ and $\Delta$ are the load, load point displacement, thickness, crack extension length and correction factor. The correction factor is found by the relationship between a compliance $\mathrm{C}$ of the equation (3) and a crack extension length.

$$
C=\frac{\delta}{P}
$$

The correction factor $\Delta$ is obtained from the size 
of the slope-intercept axis passing crack length axis. Size of $\Delta$ is to complement the deviation of the crack extension length because that a crack tip area is not completely fixed.

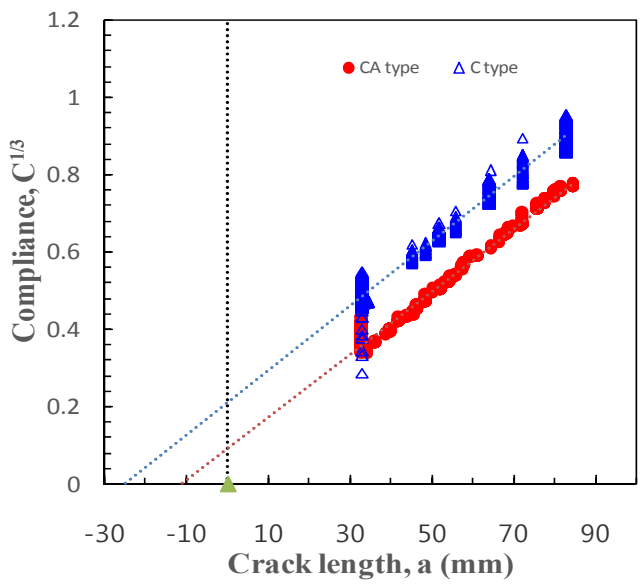

Fig. 7 The correction factor from the relationship between compliance and crack length

Fig. 7 shows the correction factor $\Delta$ obtained from the relationship between compliance and crack length. In the case of CA type specimen, $\Delta$ was $-6.674 \mathrm{~mm}$, and about $-24.13 \mathrm{~mm}$ for $\mathrm{C}$ type specimen. Using the correction factor, the energy release rate by the equation (2) is shown in Fig. 8.

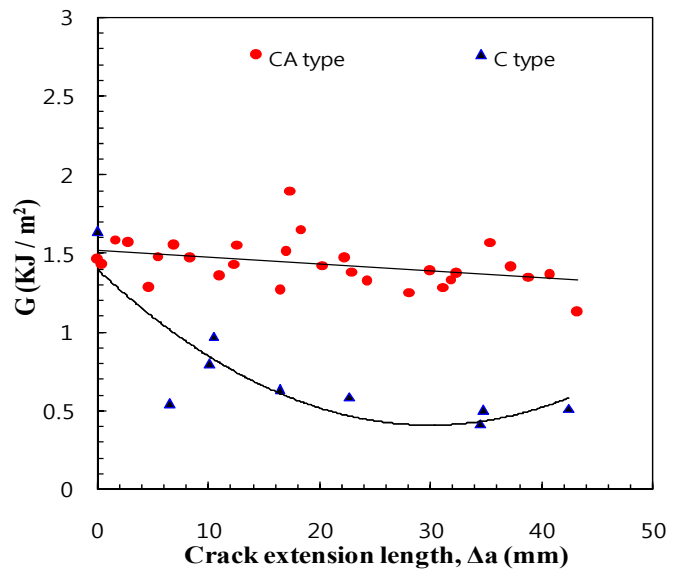

Fig. 8 The variation of the energy release rate according to the crack extension length
The energy release rate fracture toughness $\mathrm{G}_{\mathrm{IC}}$ is $1.461 \mathrm{~kJ} / \mathrm{m}^{2}$ for a CA type specimen, and about $1.643 \mathrm{~kJ} / \mathrm{m}^{2}$ for $\mathrm{C}$ type specimen. However after the crack initiated, the energy release rate decreased sharply in the $\mathrm{C}$ type specimen while $\mathrm{G}$ of CA type specimen was hardly decreased. This result represents sufficiently that the aluminum oxide powder in $\mathrm{CA}$ type specimen inhibits the crack growth in the interface of laminate CFRP composite.

\subsection{AE characteristics evaluation under DCB test}

Fig. 9(a), (b) show the relationships between $\mathrm{AE}$ amplitude and crack extension length for real time. The AE amplitude represents the scale of damage when the crack extends. The threshold value $43 \mathrm{~dB}$ was determined from which there is no occurrence of $\mathrm{AE}$ amplitude in the initial load state under the fracture test. And the mechanical and electrical noise below $43 \mathrm{~dB}$ was minimized. Fig. 9(a) shows 47.2dB value of $\mathrm{AE}$ amplitude in $\mathrm{CA}$ type specimen occurs at $311 \mathrm{sec}$ even though the crack is not initiated. This situation means the initial fatigue crack length has a measurement deviation to the right and left side. After that, the $\mathrm{AE}$ amplitude was obtained as $59.4 \mathrm{~dB}$ at $461 \mathrm{sec}$ which the crack initiates. The maximum $\mathrm{AE}$ amplitude is $62.5 \mathrm{~dB}$ at $1926 \mathrm{sec}$ and has almost about 50 60dB values during the fracture. Fig. 9(b) shows the AE amplitude and crack extension length according to the time in $\mathrm{C}$ type specimen. The first $\mathrm{AE}$ amplitude occurs at $452 \mathrm{sec}$ by $55.2 \mathrm{~dB}$ as like the $\mathrm{CA}$ type specimen. And $\mathrm{AE}$ amplitude was obtained as $62.7 \mathrm{~dB}$ at $478 \mathrm{sec}$. The maximum $\mathrm{AE}$ amplitude was $70.4 \mathrm{~dB}$.

Therefore the average $\mathrm{AE}$ amplitude of $\mathrm{C}$ type specimen is higher than that of CA type specimen. This result means that the size of damage to the crack growth in $\mathrm{C}$ type specimen is greater than in CA type specimen. 


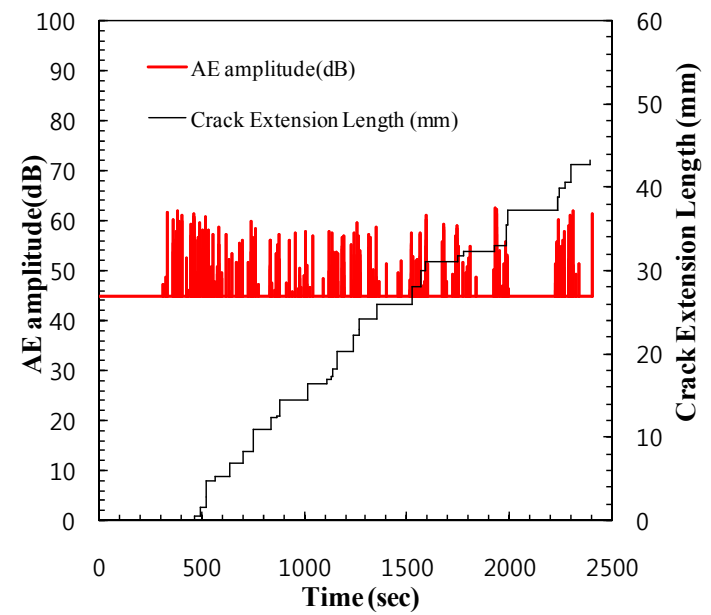

(a) CA type specimen

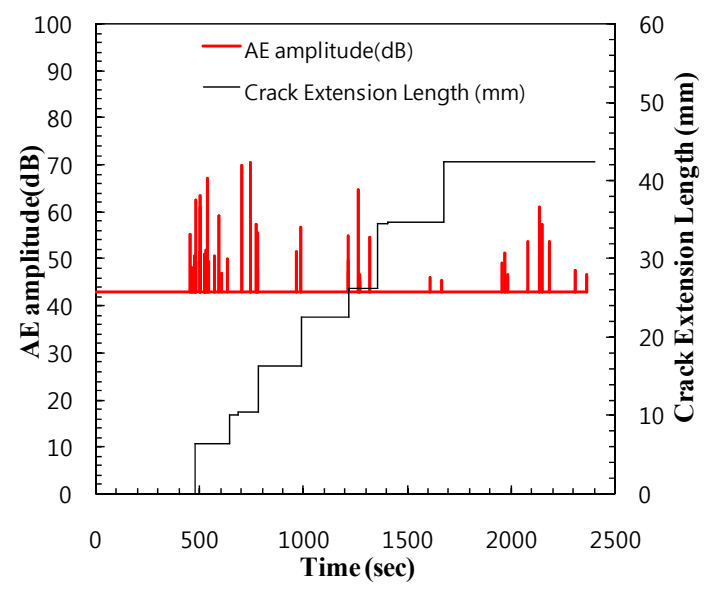

(b) C type specimen

Fig. 9 The relationships between AE amplitude and crack extension length

\section{Conclusions}

The experiments were carried out to compare and evaluate the mechanical behaviors for a CFRP composite with aluminum oxide powder, which is a reinforcement of the interlayer in laminated composite by a $\mathrm{DCB}$ test specimen with the $\mathrm{AE}$ sensor. The results were as follows.

(1) The elastic modulus and poisson's ratio are $54.12 \mathrm{GPa}$ and 0.05 for CA type specimen.
(2) The crack initiated at $35 \mathrm{~N}$ and the maximum load was $37.5 \mathrm{~N}$ for $\mathrm{CA}$ type and $49 \mathrm{~N}$ for C type specimen.

(3) The mode I fracture toughness $\mathrm{K}_{\mathrm{IC}}$ is about $2.91 \mathrm{MPa} \cdot \mathrm{m}^{1 / 2}$ and $4.41 \mathrm{MPa} \cdot \mathrm{m}^{1 / 2}$ in $\mathrm{CA}$ type and $\mathrm{C}$ type specimen, respectively.

(4) The energy release rate fracture toughness $\mathrm{G}_{\mathrm{IC}}$ is $1.461 \mathrm{~kJ} / \mathrm{m}^{2}$ for CA type specimen, and about $1.643 \mathrm{~kJ} / \mathrm{m}^{2}$ for $\mathrm{C}$ type specimen. However after the crack initiated, the energy release rate decreased sharply in the $\mathrm{C}$ type specimen while $\mathrm{G}$ of CA type specimen was hardly decreased.

(5) The $\mathrm{AE}$ amplitude was obtained as $59.4 \mathrm{~dB}$ at $461 \mathrm{sec}$ which the crack initiates. The maximum $\mathrm{AE}$ amplitude is $62.5 \mathrm{~dB}$ at $1926 \mathrm{sec}$ and has almost about $50 \sim 60 \mathrm{~dB}$ values during the fracture.

(6) The spreaded aluminum oxide powder layer in CA type specimen seems to inhibit the crack extension in the interface of CFRP laminate composite.

\section{References}

1. C. A. Mahieux, 2001, "Cost effective manufacturing process of thermoplastic matrix composites for the traditional industry: the example of carbon-fiber reinforced thermoplastic flywheel", Composite Structures, Vol. 52, pp. 517-521.

2. C. T. Sun, and M. G. Manobaran, 1983, "Growth of Delamination Crack due to in [90/0/90] Laminate", Journal of Composite Materials, Vol. 17, pp. 127-136.

3. Y. S. Yun, and O. H. Kwon, 2005, "The Evaluation of Interlaminar Fracture Toughness and $\mathrm{AE}$ Characteristic in a Plain Woven CFRP Composite With DCB Specimen", Journal of the KOSOS, Vol. 20, No. 1, pp. 49-54.

4. S. C. Park, S. S. Kang, G. Y. Kim, and J. H. Choi, 2013, "Evaluation of tensile strengths and 
fracture toughness of plain weave composites", Journal of the Korean Society of Marine Engineering, Vol. 37, No. 8, pp. 862-868.

5. S. J. Park, J. S. Oh, J. R. Lee, and K. Y. Rhee, 2003, "Effect of Surface Treated SiC on Thermal Stability and Mechanical Interfacial Properties of Carbon Fiber/Epoxy Resin Composites", Journal of the Korean Society for Composite Materials, Vol. 16, No. 3, pp. 25-31.

6. P. E. Keary and L. B. Ilcewicz, 1985, "Mode I Interlaminar Fracture Toughness of Composites Using Slender Double Cantilevered Materials, Vol. 19, pp. 145-177.

7. Standard Test Method for "Tensile Properties of Polymer Matrix Composite Materials", ASTM D 3039, 2000.

8. Standard Test Method for "Mode I Interlaminar Fracture Toughness of Unidirectional Fiber Reinforced Polymer Matrix Composites", ASTM D 5528 - 01, 2000.

9. Z. Li, 1996, "A new technique for determining fracture toughness $\mathrm{K}_{\mathrm{IC}}$ and its confidence with single DCB specimen", Engineering Fracture Mechanics, Vol. 55, pp. 133-137. 